\title{
Evolution of Erythromycin Resistance among Streptococcus pneumoniae Isolates in Malaysia from 2005 and 2010
}

\author{
Revathy Arushothy', Norazah Ahmad1, Rohani Md Yassin² \\ ${ }^{1}$ Bacteriology Unit, Infectious Disease Research Center, Institute for Medical Research, Kuala Lumpur, Malaysia \\ ${ }^{2}$ Special Diagnostic Research Center, Institute for Medical Research, Kuala Lumpur, Malaysia \\ Email: revathyaru@gmail.com
}

Received 14 January 2016; accepted 27 May 2016; published 30 May 2016

Copyright (C) 2016 by authors and Scientific Research Publishing Inc.

This work is licensed under the Creative Commons Attribution International License (CC BY).

http://creativecommons.org/licenses/by/4.0/

(c) (i) Open Access

\section{Abstract}

Objectives: This study focuses on the antibiotic susceptibility pattern and distribution of the ermB and mefA virulence genes among the Streptococcus pneumoniae due to an increase in erythromycin resistance in $S$. pneumoniae worldwide. Methodology: We investigated 255 clinical isolates collected from 2005-2010 to determine the serotype distribution and resistance to erythromycin in comparison to penicillin, clindamycin, clarithromycin, azithromycin, and trimethoprim sulfamethoxazole. Multiplex PCR was carried out to detect erythromycin resistance genes (ermB and mefA). Results: There were $146(57.3 \%)$ isolates resistant to erythromycin. MIC 90 for erythromycin is at $>256 \mathrm{mg} / \mathrm{L}$ and $\mathrm{MIC}_{50}$ is at $16 \mathrm{mg} / \mathrm{L}$. The $\mathrm{ermB}$ gene was detected in $25.3 \%$ of the erythromycin-resistant isolates and mefA gene was detected in $\mathbf{5 0 . 7 \%}$ of the isolates. The four most common serotypes encountered are $19 \mathrm{~F}, 19 \mathrm{~A}, 23 \mathrm{~F}$ and 14 . The serotype distribution among the erythromycin resistant isolates was 19F (42.0\%) followed by serotype 19A (11.3\%), serotype 23F (9.2\%) and serogroup $14(7.0 \%)$. Conclusion: In conclusion, there is a significant rise in erythromycin resistance among the Malaysian pneumococcal isolates. The emergence of serotype 19A together with increasing prevalence of resistance to macrolide warrants for a more extensive surveillance study.

\section{Keywords}

Streptococcus pneumoniae, Pneumococcal, Erythromycin Resistance, Serotype, mefA, ermB

\section{Introduction}

Streptococcus pneumoniae is one of the most common causative pathogens of severe invasive infections among

How to cite this paper: Arushothy, R., Ahmad, N. and Md Yassin, R. (2016) Evolution of Erythromycin Resistance among Streptococcus pneumoniae Isolates in Malaysia from 2005 and 2010. Journal of Biosciences and Medicines, 4, 116-122. 
infants and young children causing diseases ranging from otitis media, sinusitis, pneumonia, septicemia to meningitis. The morbidity and mortality rates of pneumococcal infections worldwide are high, particularly in developing countries. The World Health Organization (WHO) estimates the annual incidence of invasive pneumococcal disease ranging from 10 to 100 cases per 100,000 population in Europe and the United States. In the developing countries, the incidence of pneumococcal disease in children aged $<5$ years is several times higher than it is in industrialized countries [1]. A study by Kilgore P.E. et al. (2005) in China, South Korea, and Vietnam estimated the incidence of pneumococcal meningitis in children aged 1 to 23 months at 5.1 cases per 100,000 childbirths from 1999 to 2003 [2].

Studies by the Asian Network for Surveillance of Resistant Pathogens (ANSORP) have indicated that the rates of antimicrobial resistance among S. pneumoniae isolates in Asia continue to be in an increasing trend [3]. The ANSORP surveillance also documented that during 1996 and 1997, the prevalence rate of erythromycin resistance among S. pneumoniae clinical isolates was more than $60 \%$ in many areas including Taiwan, Korea, Japan and Vietnam. In Malaysia, we have observed a rise in penicillin-resistant S. pneumoniae (PRSP) from $0.8 \%$ in 1988 [4] to $7.0 \%$ in 1995 [5] and 25.54\% in 2009 [6]. Another study in Malaysia [7] has reported higher resistant rate to other common oral antibiotics in comparison to another study [5] whereby resistance to erythromycin has increased from $1.1 \%$ to $33.33 \%$ and clindamycin from $0.4 \%$ to $18.08 \%$.

To date, it has been reported that 93 pneumococcal serotypes exist which are further classified into 46 pneumococcal serogroups [8]. A study by Song et al. (2004) reported that the main serotypes among the erythromycin resistant isolates in Asia were 19F, 19A, 23A, 23F, 6A, 6B, 14, serogroup 4 and serogroup 18 [9]. Reports from Malaysia [7] indicated that the main serotypes were 19F, 19A, 6B, 14, 19B, 23F, 6A, serogroup 1, 23A, 19C and serogroup 15. This shows that there are some changes to the serotypes distribution in the last 5 years.

In particular, macrolide resistance among Streptococcus pneumoniae isolates has risen in recent years worldwide [10]. The main mechanisms of erythromycin resistance in $S$. pneumoniae are the ribosomal methylation encoded by the ermB gene ( $\mathrm{MLS}_{\mathrm{B}}$ phenotype) and macrolide efflux encoded by the mefA, mefE and mefI gene (M pneotype). Erythromycin-ribosomal methylase, which is encoded by the erm(B) gene is encoded by the methylation of adenine at position 2059 in the 23SrRNA blocks, the binding of macrolides (e.g., erythromycin), lincosamides (e.g., clindamycin), and streptogramin B (e.g., dalfopristin) and results in high-level resistance to these antibiotics (MLSB phenotype), with high erythromycin MICs ( $\geq 256 \mu \mathrm{g} / \mathrm{ml}$ ) [11].

This study was conducted to determine the distribution of the ermB gene and mefA gene and its relationship with serotype distribution and macrolide drugs susceptibility. Through this study, we wish to provide the latest scenario of antibiotic resistance in Malaysia and develop an up-to-date guideline for the management of the prescribed antimicrobials.

\section{Material and Methods}

\subsection{S. pneumoniae Isolates}

Streptococcus pneumoniae isolates $(\mathrm{n}=255)$ from clinical samples were collected from several state hospitals throughout Malaysia between 2005 to 2010. The isolates were identified as S. pneumoniae based on typical colony morphology, gram staining, $\alpha$-hemolysis, optochin (Oxoid Company, Britain) susceptibility and positive bile solubility test. The isolates were stored at $-70^{\circ} \mathrm{C}$ in $5 \%$ trypticase soy broth plus $20 \%$ (v/v) glycerol with beads [12] and were supplemented with three drops of rabbit serum for long term storage. The source of the specimen is listed below.

\begin{tabular}{cccc}
\hline \multicolumn{1}{c}{ Invasive $(\mathrm{n}=147)$} & & Non-Invasive $(\mathrm{n}=108)$ \\
\hline Blood & 109 & Sputum & 65 \\
CSF & 9 & Middle Ear Fluid & 13 \\
Tracheal Aspirates & 29 & Other & 30 \\
Children (0 - 18 years) & 110 & Children (0 - 18 years) & 37 \\
Adult & 37 & Adult & 37 \\
\hline
\end{tabular}




\subsection{Antimicrobial Susceptibility Testing}

Susceptibility to oxacillin, erythromycin, clindamycin, clarithromycin, azithromycin and trimethoprim-sulfamethoxazole (cotrimoxazole) were determined by Kirby-Bauer method disc diffusion method, by using MuellerHinton agar supplemented with 5\% sheep blood. The results were interpreted based on the Clinical Laboratory Standards Institute (CLSI) guidelines (2010). The plates were incubated at $35^{\circ} \mathrm{C}$ for 18 - 24 hours under $5 \% \mathrm{CO}_{2}$. S. pneumoniae ATCC 49619 was used as the quality control strain. Multidrug-resistant S. pneumoniae (MDRSP) was defined as those which are resistant to three or more classes of antibiotics used in this study. An E-test (AB Biodisk, Sweden) method was applied to determine the Minimum Inhibitory Concentration for two drugs, in particular, Penicillin G (256 $\mu \mathrm{g} / \mathrm{ml})$ and Erythromycin $(256 \mu \mathrm{g} / \mathrm{ml})$. S. pneumoniae ATCC 49619 was used as the quality control strain and was included in each set of tests to ensure the accuracy of the results. MICs that fell between any two doubling dilutions were rounded up to the next higher one and the susceptibility categories were then assigned according to MIC $(\mu \mathrm{g} / \mathrm{ml})$ breakpoints, as in the CSLI guidelines. The interpretive breakpoints for S. pneumoniae isolate to define penicillin and erythromycin resistance: MICS of $\geq 2 \mu \mathrm{g} / \mathrm{ml}$ and 0.5 $\mu / \mathrm{ml}$ respectively.

\subsection{Determination of Macrolide Resistance Mechanism}

The macrolide resistance genes ermB and mefA were subjected to PCR analysis to detect ermB and mefA genes as described elsewhere [10].

\subsection{Serotyping and PCV7 Coverage}

The isolates streaked on sheep blood agar and grown for 18 hours at $35^{\circ} \mathrm{C}$ in $5 \% \mathrm{CO}_{2}$, were serogroup based on the Quellung Reaction using Pneumotest kits (StatensSeruminstitut, Copenhagen, Denmark) [13]. Further serotyping was performed using type-specific antisera. The isolates that reacted negatively and could not be serotyped with the Pneumotest kit were classified as not-typeable.

\section{Results}

\subsection{Erythromycin Resistance among $S$, pneumoniae Isolates}

Among the 255 isolates, 100 (39.2\%) were susceptible, 9 (3.5\%) intermediate and 146 (57.3\%) resistant to erythromycin. In 2009, the erythromycin resistance was the highest at (67.3\%), followed by 2010 (62.2\%), 2007 (61.1\%), 2008 (52.4\%), 2006 (51.2\%) and 2005 (46.2\%). These data shows that there is an increase in the erythromycin resistance from 2005 to 2010. The $\mathrm{MIC}_{90}$ s for erythromycin among the isolates were $256 \mathrm{ug} / \mathrm{ml}$ or higher throughout 2005 to 2010 (Table 1).

\subsection{Correlation between Erythromycin Resistance and Other Drug Resistance}

About $88.1 \%$ of the erythromycin resistant pneumococci are resistant to penicillin. Clarithromycin and azithromycin are both macrolide similar to erythromycin. About $94.4 \%$ of erythromycin resistant $S$. pneumoniae isolates were also resistant to clarithromycin and azithromycin. The high resistance within macrolide group might be due to the resistance conferred by the resistance genes. Approximately $90.8 \%$ of the erythromycin resistant isolates were also resistant to trimethoprim-sulfamethoxazole.

\subsection{Serotype Distribution of the Erythromycin Resistant Isolates}

Serotypes detected among the Malaysian isolates were 14, 17F, 18F, 19A, 19F, 23F, 6A, 6B, 7A and 9A. Isolates from serotype 19F were the most prevalent erythromycin resistant (ERSP) serotype (42.5\%), followed by serotype 19A (11.0\%), serotype 23F (8.9\%) and serogroup 14 (6.8\%). Approximately $77.0 \%$ of the S. pneumoniae isolates, serotypes were found in PCV10 and PCV 13. Of the 148 isolates, 50 are from children less than age 5 years of age and the pneumococcal serotypes are 19F (15.1\%), 19A (4.1\%), 14 (2.7\%), 23F (2.7\%), 18F (2.1\%), 6B (1.4\%), 6A (1.4\%), 7A (0.7\%) and 4.8\% of the isolates are not-typeable. About $44.2 \%$ of the pneumococci were multidrug resistant (MDRSP), the most significant serotypes being 19F (28.1\%), 19A (11.0\%) and 23F (8.9\%). Almost 32.5\% of the MDRSP isolates were isolated from children less than 5 years old (Figure 1). 
Table 1. Relationship between MIC value, susceptibility to erythromycin and detection of resistance determinants from 2005 to 2010.

\begin{tabular}{|c|c|c|c|c|c|c|c|c|c|}
\hline \multirow{2}{*}{ Year } & \multirow{2}{*}{$\begin{array}{l}\text { No of } \\
\text { isolates }\end{array}$} & \multicolumn{2}{|c|}{$\begin{array}{l}\text { Minimal inhibitory } \\
\text { concentration (ug/ml) }\end{array}$} & \multicolumn{3}{|c|}{$\begin{array}{l}\text { Susceptibility to erythromycin } \\
\text { (n) \% }\end{array}$} & \multicolumn{3}{|c|}{$\begin{array}{l}\text { Resistance determinants } \\
\text { (n) \% }\end{array}$} \\
\hline & & $\mathrm{MIC}_{50}$ & $\mathrm{MIC}_{90}$ & $\mathrm{~S}^{\mathrm{a}}(\%)$ & $\mathrm{I}^{\mathrm{a}}(\%)$ & $\mathrm{R}^{\mathrm{a}}(\%)$ & erm (B) & mef (A) & $\begin{array}{c}\operatorname{erm}(\mathrm{B})+ \\
\operatorname{mef}(\mathrm{A})\end{array}$ \\
\hline 2005 & 39 & 6 & $>256$ & $20(51.3)$ & $1(2.6)$ & $18(46.2)$ & $5(27.8)$ & $9(50.0)$ & $4(22.2)$ \\
\hline 2006 & 41 & 16 & $>256$ & 18 (43.9) & $2(4.9)$ & $21(51.2)$ & $9(42.9)$ & $11(52.4)$ & $1(4.8)$ \\
\hline 2007 & 36 & 48 & $>256$ & 14 (38.9) & $0(0.0)$ & 22 (61.1) & $8(36.4)$ & $10(45.4)$ & $4(18.2)$ \\
\hline 2008 & 42 & 16 & $>256$ & $18(42.9)$ & $2(4.8)$ & $22(52.4)$ & $4(18.2)$ & 15 (68.2) & $3(13.6)$ \\
\hline 2009 & 52 & 126 & $>256$ & $15(28.8)$ & $2(3.8)$ & 35 (67.3) & $3(8.6 \%)$ & 18 (51.4) & 8 (22.9) \\
\hline 2010 & 45 & $>256$ & $>256$ & 15 (33.3) & $2(4.4)$ & $28(62.2)$ & 8 (28.6) & 11 (39.3) & $9(32.1)$ \\
\hline Total & 255 & 16 & $>256$ & 100 (39.2) & $9(3.5)$ & 146 (57.3) & 37 (25.3) & 74 (50.7) & 29 (19.9) \\
\hline
\end{tabular}

a: Isolates were defined as susceptible ( $\mathrm{S} \geq 21 \mathrm{~mm})$, intermediate (I: 16 - $20 \mathrm{~mm}$ ) and resistant ( $\mathrm{R} \leq 15 \mathrm{~mm})$ to erythromycin disc diffusion assay according to CLSI interpretation for $S$. pneumoniaee.

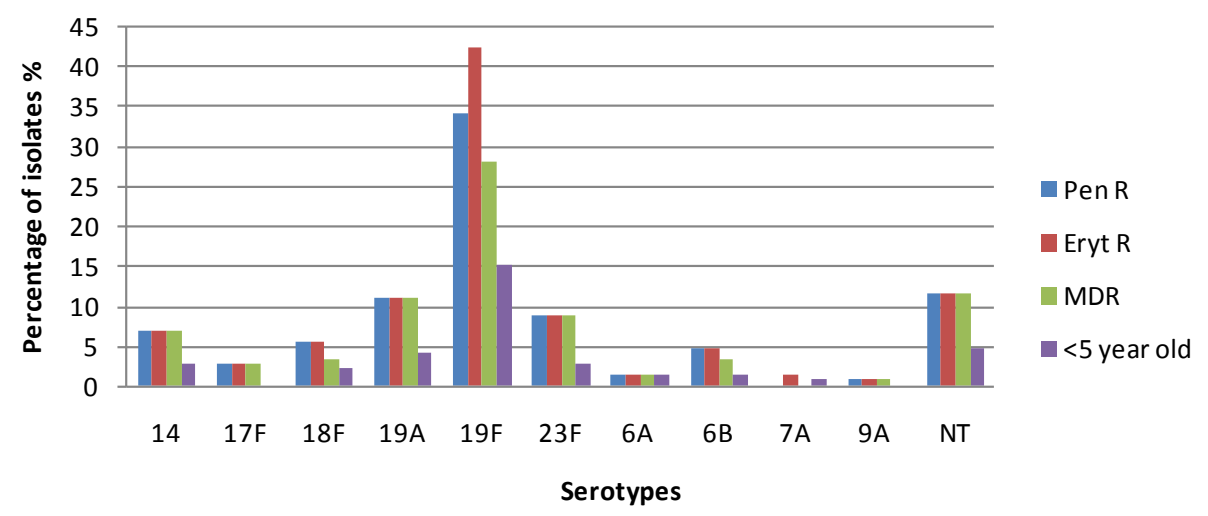

Figure 1. Distribution of S. pneumoniae serotype in Malaysia with relationship to penicillin, erythromycin and multidrug resistance with pediatric population.

\subsection{Correlation between Macrolide-Resistant Genes and Serotype Population}

The distribution of the macrolide-resistant genes can be seen as either mefA/ermB or both ermB and mefA detected together. Table 1 shows that the ermB gene was detected in $25.3 \%$ of the ERSP isolates whereas mefA gene was detected in $50.7 \%$ of the isolates. About $19.9 \%$ of the isolates were found have to the both ermB and mefA dually. The isolates with mefA gene was more common than the ermB gene among the ERSP isolates with serotype 19F (25.4\%), 19A (7.7\%), 23F (4.9\%) and $14(2.8 \%)$, whereas the ermB gene was predominant in isolates 19F (10.6\%), 23F (3.5\%), 19A (2.8\%) and 14 (2.1\%). Interestingly, 55.0\% of the ERSP isolates with both mefA and ermB gene detected dually belong to serotype 19F (Figure 2).

\section{Discussion}

An increase in macrolide resistance was observed worldwide in the past 10 years. The increment was not only documented in Malaysia but also neighboring countries [14]. In this study, the erythromycin resistance for the pneumococcal isolates has increased progressively throughout this 5 year study period. In 2005, the resistance was $46.2 \%$ and by 2010, it has increased to $62.2 \%$. The erythromycin $\mathrm{MIC}_{50}$ gradually increased from $6 \mathrm{ug} / \mathrm{ml}$ in 2005 to $>256 \mathrm{ug} / \mathrm{ml}$ in 2010. The erythromycin MIC $_{90}$ maintained at $>256 \mathrm{ug} / \mathrm{ml}$ throughout the study which reflects high resistance among the pneumococcal isolates. The increment in the MIC level, which also a clear indication of the rise in resistance shows some evidence that the increase of erythromycin consumption might be related to rise in resistance. Isolates from Hong Kong have been reported to be $80.0 \%$ resistant to erythromycin 


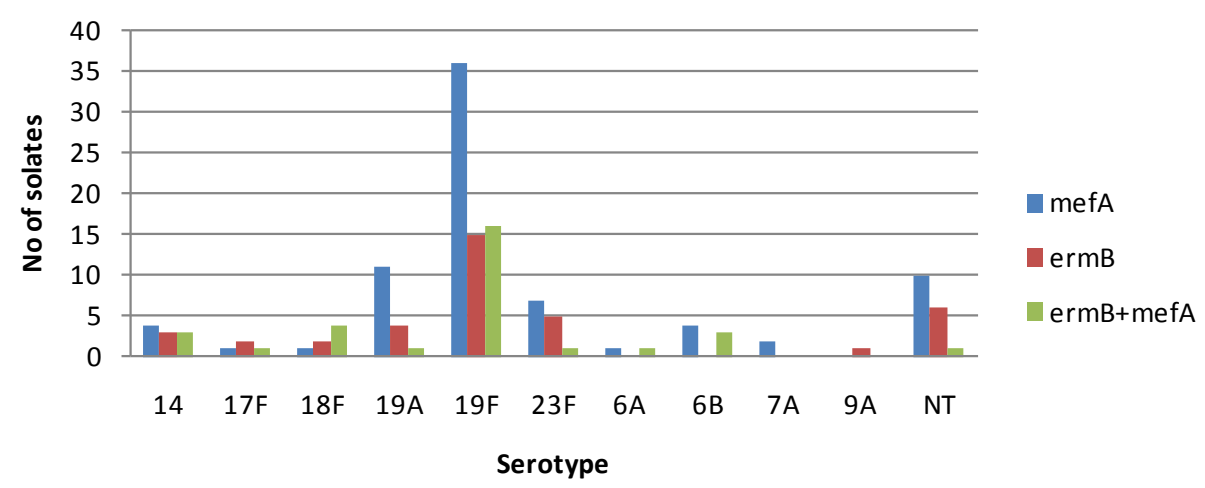

Figure 2. Relationship between ERSP serotype and distribution of macrolide-resistant genes.

[15] and $91.0 \%$ of the Taiwanese isolates were fully resistant to erythromycin [16]. According to the study by Song et al. (2004) [16] the prevalence of macrolide resistance is alarmingly high in Vietnam, Korea and China, where $>70 \%$ of the pneumococcal isolates are fully resistant to erythromycin.

About $94.4 \%$ of erythromycin resistant isolates were also resistant to clarithromycin and azithromycin. Penicillin resistance is usually concomitant with macrolide resistance, and in our study, $88.0 \%$ of the erythromycin resistance isolates were penicillin resistant. Similar findings for the trend of penicillin resistance was also reported previously [11] [17] [18]. These data provides a relatively good representation of the local pneumococcal isolates. Penicillin resistance isolates have increased progressively from 10.9\% [17], 31.0\% [18] and 25.54\% [11]. In our study, $50.2 \%$ of the 255 isolates were resistant to penicillin.

The rate of resistance to trimethoprim-sulfamethoxazole was $90.8 \%$ in the erythromycin resistant isolates. The extremely high level of resistance to trimethoprim-sulfamethoxazole among the pneumococci isolates in Malaysia is unexpected, as this antibioticin not frequently used for empirical treatment. A similar scenario was also reported by Soh S.W. (2000) [19] on pediatric isolates from Singapore.

Clindamycin resistance rate of $29.4 \%$ was detected among the 255 pneumococci isolates studied. Of the erythromycin resistant isolates, $51.2 \%$ were clindamycin resistant and had the macrolide-lincosamide-streptogramin $\mathrm{B}\left(\mathrm{MLS}_{\mathrm{B}}\right)$ phenotype.

The progressive increase in the prevalence of level of macrolide resistance among the pneumococci isolates from Malaysia draws a particular concern. Erythromycin resistance in pneumococci is due to the modification of the drug binding site which is regulated by the ermB gene, that is usually associated with the $\mathrm{MLS}_{\mathrm{B}}$ phenotype and high-level resistance to erythromycin, with $\mathrm{MIC}_{\mathrm{S}}$ of $\geq 64 \mu \mathrm{g} / \mathrm{ml}$. Low-level erythromycin resistance, with MIC $_{S}$ of 1 to $32 \mu \mathrm{g} / \mathrm{ml}$, is due to the active efflux of the drug (which is regulated by the mefA gene [20]. Molecular characterization of the macrolide-resistant isolates in this study showed that the ermB gene was found in $25.3 \%$ of the pneumococcal isolates and mefA gene was found in $50.7 \%$ of the isolates. About $19.9 \%$ of the isolates were found have to the both ermB and mefA dually. This data suggest that almost 56\% (144/255 isolates) are resistant to erythromycin and carry the resistant genes. Similar findings [21], which found more than $50 \%$ of the pneumococcal isolates from Asia carry the ermB and mefA gene. Based on these findings, it may be suggested that the use of single macrolide for the treatment of pneumococcal diseases may result in failure of antimicrobial therapy.

The four most common serotype encountered among the erythromycin pneumococcal isolates in over these 5 year study period are 19F, 19A, 23F and 14. Serotype 19F was the most prevalent erythromycin resistant serotype (42\%) followed by serotype 19A (11.3\%), serotype 23F (9.2\%) and serogroup 14 (7.0\%). Many studies, around the world, have reported the insurgence of serotype $19 \mathrm{~F}, 23 \mathrm{~F}$ and 14 among the erythromycin resistant pneumococci isolates.

The PCV7 vaccine appears to be able to confer protection against $86.1 \%$ of the local erythromycin resistant pneumococci. However, isolates from our study also show that there is an increase in the 19A serotype. The high prevalence of serotype 19A might be contributed to the reduction in disease caused by isolates from the PCV7 serotypes. Studies have shown that the proportion of serotype 19A isolates increased from $0.5 \%$ in 1995 and $0.3 \%$ during 2002-2004 to 6.93\% (2008-2009) in Malaysia [11]. An insurgence of 19A serotype among the French isolates was also reported after the introduction of the PCV7 vaccine [22]. The introduction of PCV7, 
PCV10 and PCV13 covered $60.3 \%, 66.7 \%$ and $87.8 \%$ of all isolates in China [23]. The change from PCV7 to either PCV10 or PCV13 would further improve the coverage as it has 19A serotype.

It is particularly interesting as how these serotypes are related to macrolide resistance. Other non-prevalent serotypes are also detected among the erythromycin resistant isolates. This may be due to variations in the geographical area, type of disease and age group of the patients. However, the high prevalence of erythromycin resistance in this study suggests the rapid spread of resistant clones among pneumococci in this region. Since $S$. pneumoniae has the ability to switch serotypes by horizontal transfer recombination [20] and other genetic events, it is important to monitor the frequency of the serotype exchanges in order to predict long-term efficacy of the new vaccine. Therefore continuous monitoring of antimicrobial resistance and serotype distribution of $S$. pneumoniae is important for disease management and implementation of disease control policies in Malaysia. The current study needs the support of a long-term surveillance program, epidemiological typing and also vaccination data for prevention and control of pneumococcal infections.

\section{Conclusion}

In conclusion, there is a significant rise in macrolide resistance among the Malaysian pneumococcal isolates. The rise of the 19A serotype is most likely linked to the introduction to PCV7. However, the emergence of serotype 19A together with increasing prevalence of resistance to macrolide warrants for a continuous surveillance of pneumococcal serotypes and a more extensive antimicrobial study.

\section{Conflict of Interest}

The authors declare that they have no conflict of interests.

\section{Acknowledgements}

The authors thank the Director General of Health, Ministry of Health Malaysia for permission to publish this paper. This study was conducted using the research grant from National Institute of Health, project code JPPIMR-08-007. The authors would also like to thank the staff of Bacteriology Unit, Institute for Medical Research for their contribution and technical support.

\section{References}

[1] WHO (2007) Pneumococcal Conjugated Vaccine for Childhood Immunization. Weekly Epidemiological Record, 82, 93-104.

[2] Kilgore, P.E., Kennedy, W.A., Anh, D.D., Nyambat, B., Kim, J.S., et al. (2005) Epidemiology of Childhood Pneumococcal Meningitis in China, South Korea and Vietnam, 1999 through 2003: Implications for Estimating the Burden of Disease and Prevention through Immunization. 43rd Annual Meeting of the Infectious Diseases Society of America, 6-9 October 2005, 142.

[3] Song, J.H., Jung, S.I., Ko, K.S., Kim, N.Y., Son, J.S., Chang, H.H., Ki, H.K., Oh, W.S., Suh, J.Y., Peck, K.R., Lee, N.Y., Yang, Y.H., Lu, Q., Chongthaleong, A., Chiu, C.H., Lalitha, M.K., Perera, J., Yee, T.T., Kumarasinghe, G., Jamal, F., Kamarulzaman, A., Parasakthi, N., Van, P.H., Carlos, C., So, T., Ng, T.K. and Shibl, A. (2004) High Prevalence of Antimicrobial Resistance among Clinical Streptococcus pneumoniae Isolates in Asia (an ANSORP Study). Antimicrobial Agents and Chemotherapy, 48, 2101-2107. http://dx.doi.org/10.1128/AAC.48.6.2101-2107.2004

[4] Cheong, Y.M., Jegathesan, M., Henrichsen, J. and Wong, Y.H. (1988) Antibiotic Susceptibility and Serotype Distribution of S. pneumoniae in Malaysian Children. Journal of Tropical Pediatrics, 34, 182-185. http://dx.doi.org/10.1093/tropej/34.4.182

[5] Rohani, M.Y., Raudzah, A., Ng, A.J., Ng, P.P., Zaidatul, A.A., Asmah, I., et al. (1999) Epidemiology of S. pneumoniae Infection in Malaysia. Epidemiology \& Infection, 122, 77-78. http://dx.doi.org/10.1017/S0950268898001605

[6] Ministry of Health Malaysia (2009) Unpublished Data from National Surveillance of Antibiotic Resistance.

[7] Rohani, M.Y., Zin, N.M., Hussin, A., Nawi, S.H., Hanapiah, S.M., et al. (2011) Current Trend of Pneumococcal Serotypes Distribution and Antibiotic Susceptibility Pattern in Malaysian Hospitals. Vaccine, 29, 5688-5693. http://dx.doi.org/10.1016/j.vaccine.2011.06.004

[8] Jones, R.N., Jacobs, M.R. and Sader, H.S. (2010) Evolving Trends in Streptococcus pneumoniae Resistance: Implications for Therapy of Community-Acquired Bacterial Pneumonia. International Journal of Antimicrobial Agents, 36, 197-204. http://dx.doi.org/10.1016/j.ijantimicag.2010.04.013 
[9] Ip, M., Lyon, D.J., Yung, R.W., Chan, C. and Cheng, A.F. (2001) Macrolide Resistance in Streptococcus pneumoniae in Hong Kong. Antimicrobial Agents and Chemotherapy, 45, 1578-1580. http://dx.doi.org/10.1128/AAC.45.5.1578-1580.2001

[10] Farrell, D.J., et al. (2003) Macrolide Resistance by Ribosomal Mutation in Clinical Isolates of Streptococcus pneumoniae from the PROTEKT 1999-2000 Study. Antimicrobial Agents and Chemotherapy, 47, 1777-1783. http://dx.doi.org/10.1128/AAC.47.6.1777-1783.2003

[11] Adam, D. (2000) Global Antibiotic Resistance in Streptococcus pneumoniae. Journal of Antimicrobial and Chemotheraphy, 50, 1-5. http://dx.doi.org/10.1093/jac/dkf801

[12] Desa, M.N., Thong, K.L., Rohani, M.Y. and Parasakthi, N. (2003) Penicillin Susceptibility and Molecular Characteristics of Clinical Isolates of Streptococcus pneumoniae at the University of Malaya Medical Center, Kuala Lumpur, Malaysia. International Journal of Infectious Diseases, 7, 190-197. http://dx.doi.org/10.1016/S1201-9712(03)90051-8

[13] Hsueh, P.-R. and Luh, K.-T. (2002) Antimicrobial Resistance in Streptococcus pneumoniae, Taiwan. Emerging Infectious Diseases, 8, 1487-1491. http://dx.doi.org/10.3201/eid0812.020178

[14] Song, J.H., Chang, H.H., Suh, J.Y., Ko, K.S., Jung, S.I., Oh, W.S., Peck, K.R., Lee, N.Y., Yang, Y., Chongthaleong, A., Aswapokee, N., Chiu, C.H., Lalitha, M.K., Perera, J., Yee, T.T., Kumararasinghe, G., Jamal, F., Kamarulazaman, A., Parasakthi, N., Van, P.H., So, T. and Ng, T.K. (2004) Macrolide Resistance and Genotypic Characterization of Streptococcus pneumoniae in Asian Countries: A Study of the Asian Network for Surveillance of Resistant Pathogens (ANSORP). Journal of Antimicrobial Chemotherapy, 53, 457-463. http://dx.doi.org/10.1093/jac/dkh118

[15] Rohani, M.Y., Parasakthi, N., Raudzah, A. and Yasim, M.Y. (1999) In-Vitro Susceptibilities of Streptococcus pneumoniae Strains Isolated in Malaysia to Six Antibiotics. Journal of Antimicrobial Chemotherapy, 44, 852-853. http://dx.doi.org/10.1093/jac/44.6.852

[16] Soh, S.W., Poh, C.L. and Lin, R.V. (2000) Serotype Distribution and Antimicrobial Resistance of Streptococcus pneumoniae Isolates from Pediatric Patients in Singapore. Antimicrobial Agents and Chemotherapy, 44, 2193-2196. http://dx.doi.org/10.1128/AAC.44.8.2193-2196.2000

[17] Song, J.H., Chang, H.H., Suh, J.Y., Ko, K.S., Jung, S.I., Oh, W.S., Peck, K.R., Lee, N.Y., Yang, Y., Chongthaleong, A., Aswapokee, N., Chiu, C.H., Lalitha, M.K., Perera, J., Yee, T.T., Kumararasinghe, G., Jamal, F., Kamarulazaman, A., Parasakthi, N., Van, P.H., So, T. and Ng, T.K. (2004) Macrolide Resistance and Genotypic Characterization of Streptococcus pneumoniae in Asian Countries: A Study of the Asian Network for Surveillance of Resistant Pathogens (ANSORP). Journal of Antimicrobial Chemotherapy, 53, 457-463. http://dx.doi.org/10.1093/jac/dkh118

[18] Mahjoub-Messai, F., et al. (2009) Population Snapshot of Streptococcus pneumoniae Serotype 19A Isolates before and after Introduction of Seven-Valent Pneumococcal Vaccination for French Children. Journal of Clinical Microbiology, 47, 837-840. http://dx.doi.org/10.1128/JCM.01547-08

[19] Xue, L., Yao, K.H., Xie, G.L., Zheng, Y.J., Wang, C.Q., et al. (2010) Serotype Distribution and Antimicrobial Resistance of Streptococcus pneumoniae Isolates That Cause Invasive Disease among Chinese Children. Clinical Infectious Diseases, 50, 741-744. http://dx.doi.org/10.1086/650534

[20] Dobay, O., Rozgonyi, F., Hajdu, E., Nagy, E., Knausz, M., et al. (2003) Antibiotic Susceptibility and Serotypes of Streptococcus pneumoniaeisolates from Hungary. Journal of Antimicrobial Chemotherapy, 51, 887-893. http://dx.doi.org/10.1093/jac/dkg171

[21] Le, C.-F., Palanisamy, N.K., Yusof, M.Y. and de Sekaran, S. (2011) Capsular Serotype and Antibiotic Resistance of Streptococcus pneumoniae Isolates in Malaysia. PLoS ONE, 6, Article ID: e19547. http://dx.doi.org/10.1371/journal.pone.0019547

[22] Obaro, S.K., Montell, M.A. and Henderson, D.C. (1996) The Pneumococcal Problem. BMJ, 312, 1521-1525. http://dx.doi.org/10.1136/bmj.312.7045.1521

[23] Hyams, C., Camberlein, E., Jonathan, M., Cohen, M., Bax, K., et al. (2010) The Streptococcus pneumoniae Capsule Inhibits Complement Activity and Neutrophil Phagocytosis by Multiple Mechanisms. Infection and Immunity, 78, 704715. http://dx.doi.org/10.1128/IAI.00881-09 